\title{
International
}

\section{APSA Renews Engagement with Early-Career Political Scientists from the Arab Middle East and North Africa: MENA Workshops 2019-2021}

Andrew Stinson, Director of International Programs, American Political Science Association

\section{A}

PSA has been awarded $\$ 700,000$ to expand our engagement with political scientists in the Arab Middle East and North Africa. With renewed support from the Carnegie Corporation of New York, APSA will continue to offer highimpact training and long-term networking opportunities that build the capacity of MENA region scholars to publish empirically-rich analyses of emerging issues in political science

The APSA MENA Workshops are annual capacity-building programs that bring together approximately 20 fellows, alongside four senior scholars, for training in research skills, professional development, peer-review, and networking. The program is open to $\mathrm{PhD}$ candidates, postdocs, and early-career faculty from across the Arab Middle East and North Africa. Each workshop is dedicated to a substantive issue in political science with a unique schedule of lectures, discussions, research presentations, guest speakers, and professional development seminars. Throughout the workshops, fellows receive critical feedback on their research and work to refine these manuscripts for publication. In the process, fellows form important professional networks of peer-review, support, and collaboration. Following their participation in the workshop, alumni are given complimentary membership to APSA and are eligible to apply for grants to facilitate

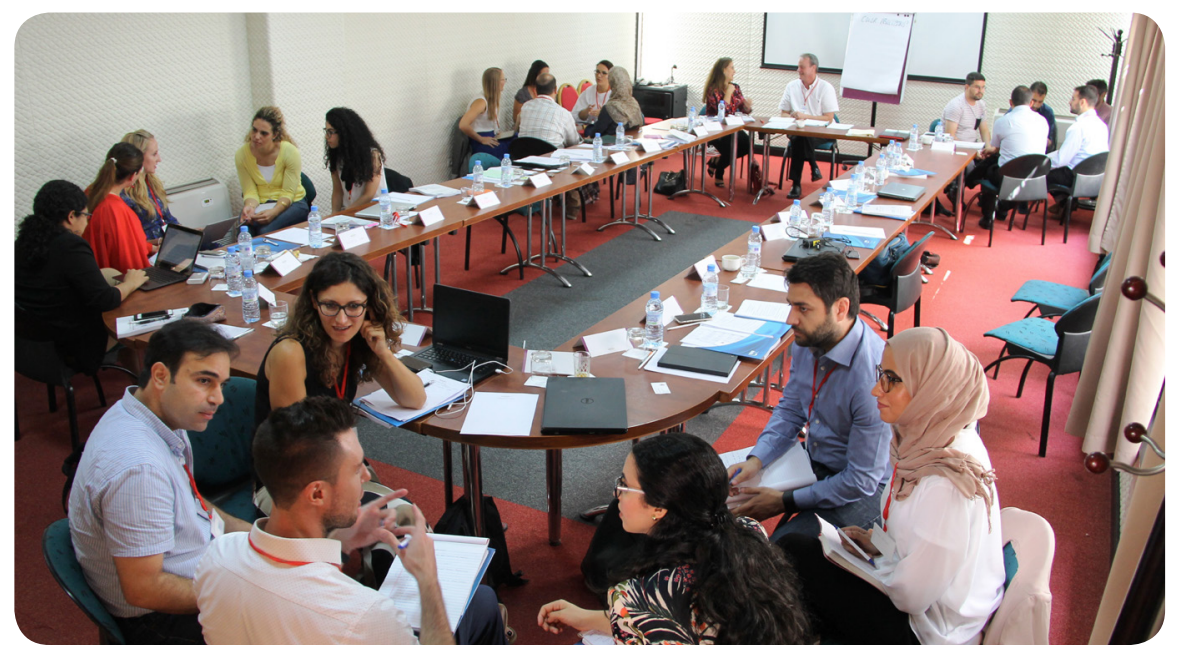

Above: Small group discussions at the September 2018 MENA Workshop in Rabat, Morocco. further professional development and research collaboration.

Aside from the workshops, APSA supports rigorous training in quantitative and qualitative research methods through partnerships with the Inter-University Consortium for Political and Social Research (ICPSR) and the Institute for Qualitative and Multi-Method Research (IQMR). Each year, APSA supports up to eight social science scholars from the Arab MENA region to attend multi-week summer training programs offered by these institutions in the United States. APSA also collaborates directly with political science and related departments at MENA-region
APSA MENA PROGRAM IN BRIEF

- $\quad$ One-week residential, political science workshops networking 22 scholars from the Arab MENA region.

- Institutional support to departments of political science across the region.

- Travel grants for intensive training in quantitative and qualitative methods.

- Support for early-career scholars in the Arab Political Science Network (APSN). universities to design and organize tailored programming that supports local graduate students and faculty.

The next phase of APSA's MENA programming will include support for an emerging community of early-career Arab scholars: the Arab Political Science Network (APSN). APSN is an independent scholarly network that centers political science research and teaching in the Arab world by organizing conference panels, workshops, and other events in the MENA region. Connecting APSA's MENA Workshops alumni with this growing community and supporting their work will help generate local networking activity and promote Arabic-language capacity-building among additional scholars.

Alongside APSA's other international workshops, the MENA Program is part of a larger effort to engage with the international political science community and strengthen research networks linking US scholars with their colleagues overseas, an important part of the association's 20202022 strategic plan. For program news, updates, and additional information visit the project website: http://web.apsanet.org/ mena/ 